Volume 9, Issue 1 (Winter 2017)

\title{
Rembrandt in the Mauritshuis: Work in Progress
}

Quentin Buvelot

Q.Buvelot@mauritshuis.nl

Recommended Citation:

Quentin Buvelot, "Rembrandt in the Mauritshuis: Work in Progress," JHNA 9:1 (Winter 2017), DOI: 10.5092/jhna.2017.9.1.11

Available at https://jhna.org/articles/rembrandt-mauritshuis-work-in-progress/

Published by Historians of Netherlandish Art: https://hnanews.org/

Republication Guidelines: https://jhna.org/republication-guidelines/

Notes: This PDF is provided for reference purposes only and may not contain all the functionality or features of the original, online publication. This PDF provides paragraph numbers as well as page numbers for citation purposes.

ISSN: 1949-9833 


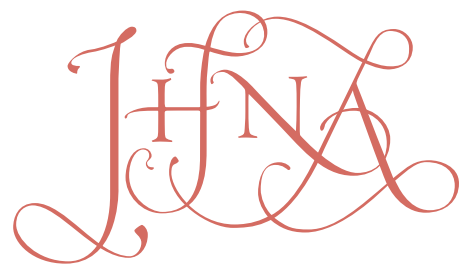

JOURNAL OF HISTORIANS OF NETHERLANDISH ART

REMBRANDT IN THE MAURITSHUIS: WORK IN PROGRESS

\section{Quentin Buvelot}

The curators and conservators at the Mauritshuis have long been engaged with an intensive study of the paintings by Rembrandt in the permanent collection. Much of the research that has been done at the Mauritshuis has been undertaken in the last decades. The challenging treatment of Saul and David is the latest of many restorations of paintings by or attributed to Rembrandt by the Mauritshuis, presently the proud owner of eleven accepted works by Rembrandt. For some works that had been seriously doubted in the past, including The Laughing Man and Tronie of a Man with a Feathered Beret, these restorations provided essential information that helped to secure their attribution to the great master. One of the paintings that has not been cleaned and restored recently is a painting that for a long time was accepted as an early self-portrait by Rembrandt (inv. 148). The attribution of the painting, now seen as a studio copy after Rembrandt, can hopefully be fine-tuned in the future. At least two works that are attributed to Rembrandt and usually kept in storage deserve more attention from the museum's conservators and curators: one is the tronie of an old man (inv. 565), another is the study of an old man (inv. 560), which bears a signature and date next to the man's shoulder: Rembrandt.f./1650. D0l:10.5092/jhna.2017.9.1.11

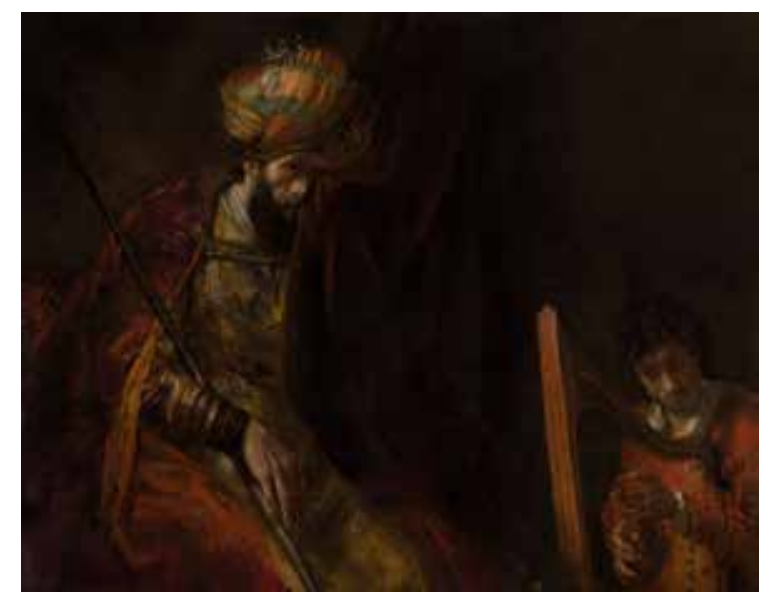

Fig. 1 Rembrandt van Rijn, Saul and David, ca. 1651-54 and ca. $1655-58$, oil on canvas, $130 \times 164.5 \mathrm{~cm}$. The Hague, Mauritshuis, Bequest of Abraham Bredius, 1946, inv. 621 (artwork in the public domain)

Walter Liedtke was one of the most productive art historians of the last decades. His books and other publications amount to a huge pile, but one stands out for its rather unique character: Rembrandt/Not Rembrandt in the Metropolitan Museum of Art, published in 1995 to accompany the exhibition of the same name, which tried to demystify the kind of research that goes on in art 
museums. The Metropolitan Museum of Art in New York took a stand by demonstrating the different approaches that art historians and art conservators take in reaching their conclusions: the first volume of the publication of works attributed to Rembrandt van Rijn (1606-1669) was written by Liedtke himself (with contributions from curatorial colleagues), the second by his colleague in the Met's conservation department, Hubert von Sonnenburg, one of the world's leading painting conservators, who died in 2004. In the two volumes they wrote on the same paintings, but they did not necessarily agree on the attribution to the artist, hence the title Rembrandt/Not Rembrandt. ${ }^{1}$ With this in mind, it is especially regrettable that because of his premature death Walter could not come to The Hague and see the exhibition Rembrandt? The Case of Saul and David in the summer of 2015, which focused on art-historical and conservation issues surrounding the famous and previously much contested Saul and David (fig. 1). Unlike the two volumes of Rembrandt/Not Rembrandt, the Mauritshuis publication presented the findings of the museum's conservators and curators with complete unanimity. It was written by the museum's director, Dr. Emilie Gordenker. ${ }^{2}$

2 Like Walter and his colleagues, curators and conservators at the Mauritshuis have long been engaged with an intensive study of the paintings by Rembrandt in the permanent collection. Much of the research that has been done at the Mauritshuis has been undertaken in the twenty years since the Met's exhibition. The recent exhibition presenting the full reattribution of Saul and David to Rembrandt is the exciting conclusion of eight years of research by a large team of international experts under the leadership of the Mauritshuis. ${ }^{3}$ The painting has been carefully restored, and the exhibition made visitors aware of the latest restoration techniques and research methods. The restored painting was not only a revelation to many visitors but also to painting conservators, curators, and other museum professionals, including a group of international curators that met in the Mauritshuis during the exhibition as part of a CODARTfocus seminar on August 31, 2015.

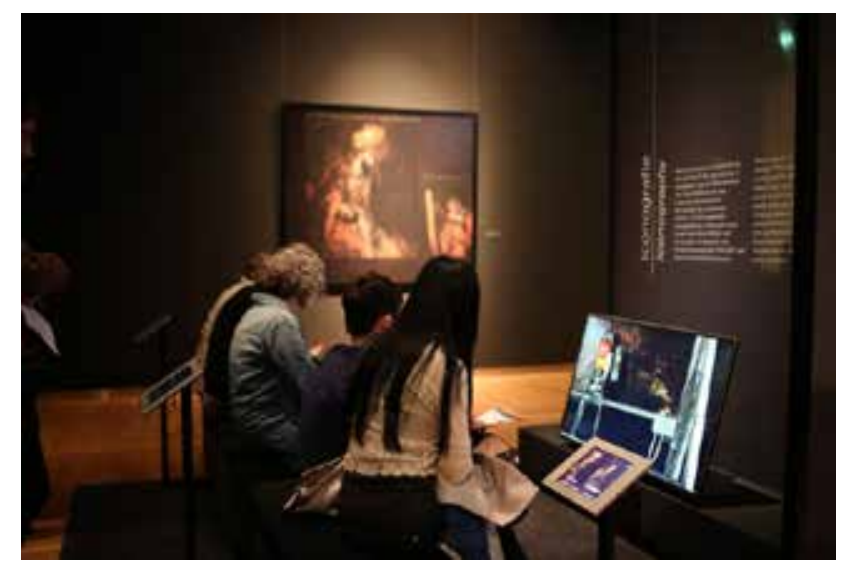

Fig. 2 The 3D reconstruction of the original size of Rembrandt's Saul and David, made by 0cé Technologies and Delft University of Technology, 2015.

3 Rembrandt's Saul and David - acquired in 1946 as part of the bequest of Abraham Bredius, the famous director of the Mauritshuis who will be discussed below-was last exhibited in 2007, after which it spent several years in the Mauritshuis conservation studio. Before its acquisition by Bredius in 1898, the canvas had been cut into two pieces and then reassembled on a new lining, most likely between 1830 and 1869. Research by the Mauritshuis conservators clearly showed that the current painting consists of no fewer than fifteen different pieces of canvas: two large pieces from the original canvas (one with Saul and one with David), with the large gap at top right 
filled in with a piece of an old canvas (an early copy after Anthony van Dyck's portrait of Isabella Clara Eugenia, governess of the Southern Netherlands) and other strips added on the edges of the painting. In addition, the original painting was larger: a three-dimensional reconstruction of the painting's original size was made especially for the exhibition by Océ Technologies in close collaboration with Delft University of Technology (fig. 2).

The challenging treatment of Saul and David is the latest of many restorations of paintings by or attributed to Rembrandt that have taken place in the Mauritshuis, presently the proud owner of eleven accepted works by Rembrandt, including Saul and David - with one exception, all these restorations have taken place in the last two decades. ${ }^{4}$ For some works that had been seriously doubted in the past, including The Laughing Man and Tronie of a Man with a Feathered Beret, these restorations provided essential information that helped to secure the attribution to the great master. Some of these paintings had belonged to the collection of the eighteenth-century Dutch stadholder William V (1748-1806), who owned Simeon's Song of Praise (inv. 145) Susanna (inv. 147) and Tronie of a Man with a Feathered Beret (inv. 149), paintings that entered the Mauritshuis collection in 1816. Twelve years later, the first king of the Netherlands, William I (1772-1843), acquired Rembrandt's celebrated Anatomy Lesson of Dr. Nicolaes Tulp (inv. 146). Much later in the nineteenth century, during the directorship of the famous art historian Abraham Bredius (18551946), a well-known Rembrandt scholar, The Laughing Man was acquired (inv. 598), a painting that came from the collection of Cornelis Hofstede de Groot (1863-1930), another famous Rembrandt scholar who for some years also worked at the Mauritshuis.

Bredius bought for his private collection as well as for the museum, and after his death in 1946 he bequeathed four Rembrandt paintings to the museum: his bequest included not only Saul and David (inv. 621), but also Andromeda (inv. 707), Homer (inv. 584), and Two Moors (inv. 685). In his will, Bredius had stipulated that his paintings would always have to remain in the Mauritshuis and could not be lent to temporary exhibitions elsewhere; as a result, the paintings were not as well studied as other works that were allowed to travel. For this reason, in 1991 the Mauritshuis organized a major show called Bredius, Rembrandt and the Mauritshuis: A Tenacious Director Collects, to coincide with the large retrospective Rembrandt exhibition in the Amsterdam Rijksmuseum. ${ }^{5}$ After the Bredius bequest, two more paintings by the artist were bought for the museum: in 1947 Rembrandt's Self-Portrait (inv. 840) and in 1999 his Portrait of an Elderly Man (inv. 1118).

At the end of the twentieth century, it was quite clear that many of the Rembrandt paintings in the Mauritshuis were in need of restoration, obscured as they were by yellowed layers of varnish and discolored retouchings. It was decided to restore the paintings and to ensure their condition for the future. The first Rembrandt to be treated by the museum's conservators was his 1632 Anatomy Lesson of Dr. Nicolaes Tulp, to which an exhibition and a book were devoted in 1998, entitled Rembrandt under the Scalpel. ${ }^{6}$ Many other restorations followed, executed by Chief Conservator Jørgen Wadum (who left the museum in 2005), his successor Petria Noble (who exchanged the Mauritshuis for the Rijksmuseum in 2014), and Carol Pottasch, Senior Conservator at the Mauritshuis. Nearly all the Rembrandt paintings have now been restored and subjected to thorough material and technical investigation by the museum's conservators, resulting in a treasure trove of new information on Rembrandt's technique, as well as many details about the material aspects and the degradation of the paint layers. It was already known that Rembrandt's Homer is a 
fragment of a much larger painting made by the artist for the Italian collector Antonio Ruffo that was severely damaged during an earthquake in Sicily in 1783. However, on the basis of archival documents and research of the canvas itself, Noble was able to reconstruct more precisely its original dimensions. In the case of another late Rembrandt, his self-portrait of 1669, Pottasch discovered that parts of the original canvas had been folded around the stretcher bars during a previous treatment, which greatly disrupted the balance of the composition as it gave the painting an almost square format. Having been attached to a slightly larger stretcher, the canvas now approaches the original format more closely; by setting the figure somewhat higher in the picture plane, the monumental character of the self-portrait was greatly enhanced.

These are just some of the interesting results of the restorations executed in the Mauritshuis; results of the material and technical investigation are far too numerous to summarize here and have been published in a plethora of scholarly periodicals and other publications over the last two decades. ${ }^{7}$ Material and technical investigations have been complemented by the more traditional art-historical research conducted by the museum's curators in the recent past, Ben Broos, Edwin Buijsen, Ariane van Suchtelen, and myself. In the Mauritshuis, conservators and curators work closely together, and the result of their collaboration has found its way into collection catalogues, such as the volumes that were devoted to history paintings and portraits and included Rembrandts. ${ }^{8}$ In 2004, a summary catalogue was published that included the complete collection of the Mauritshuis, providing an opportunity to list and fine-tune the attributions of some much debated paintings traditionally attributed to Rembrandt. ${ }^{9}$

The "bible" for research of the Rembrandts in The Hague is Rembrandt in the Mauritshuis, ${ }^{10}$ a volume that deals with all the paintings attributed to the artist and which appeared as early as 1978-four years before the first volume of the famous Corpus of Rembrandt Paintings. Research into the Mauritshuis Rembrandts started in 1968, the same year as the Rembrandt Research Project was founded. Although Rembrandt in the Mauritshuis is remarkably fresh and surprisingly modern for a book from the 1970s, and even includes some color reproductions of the paintings, the Mauritshuis has plans to publish a new edition in the coming years. In 2008, the Mauritshuis published Preserving our Heritage, entirely devoted to conservation, restoration, and technical research in the Mauritshuis. Written by the museum's conservators and curators, it includes four of the Rembrandt paintings that were restored by the museum. ${ }^{11}$ A more recent development is the Rembrandt Database, www.rembrandtdatabase.org, a joint initiative of the Netherlands Institute for Art History and the Mauritshuis. ${ }^{12}$ Its content is provided by a range of partner institutions around the world, including the Rijksmuseum and the Metropolitan Museum of Art. ${ }^{13}$ Launched in 2012, the Rembrandt Database aims, as a modern research tool, to become the first port of call for research on the artist's paintings. Besides a complete overview of the provenance, exhibition history, and literature of the paintings, the site also assembles very extensive technical documentation that, in hard format, is dispersed around the globe.

9 In considering the Rembrandt paintings that have been restored at the Mauritshuis, it is surprising how the appearance of many of them has changed since the restorations. After the removal of layers of yellowed varnish and discolored retouchings, the paintings can now be enjoyed much better than before. In 2006, four hundred years after Rembrandt's birth, all the Mauritshuis Rembrandts were installed together in the Potter Room of the museum, presenting newly 
restored paintings and many new findings. Coinciding with the exhibition, a book was published for the general reader. ${ }^{14}$ The Mauritshuis aims to present its collection in the best way possible and besides conserving and restoring the paintings, this also entails giving attention to frames. Often, when paintings are restored, frames are adapted or replaced. Sometimes this completely changes the appearance of a painting, and one of the best examples of this is the new frame made for Susanna. During the restoration of the painting, research by Petria Noble made clear that the rectangular panel was originally meant to be framed with the upper corners covered; she found that these were originally painted black by Rembrandt, only to be overpainted in the eighteenth century. As a result, in 2012 it was decided to replace the small, rather dull gilded frame from the 1930s with an imitation of a seventeenth-century frame that now covers the upper corners, which more closely approaches the original appearance of the attractive painting. Noble and the present author collaborated closely on the new frame, and in my opinion, the intimate scene of the chaste Susanna who covers her shame for two male onlookers hidden in the bushes, is much more impressive now than in its former frame. ${ }^{15}$

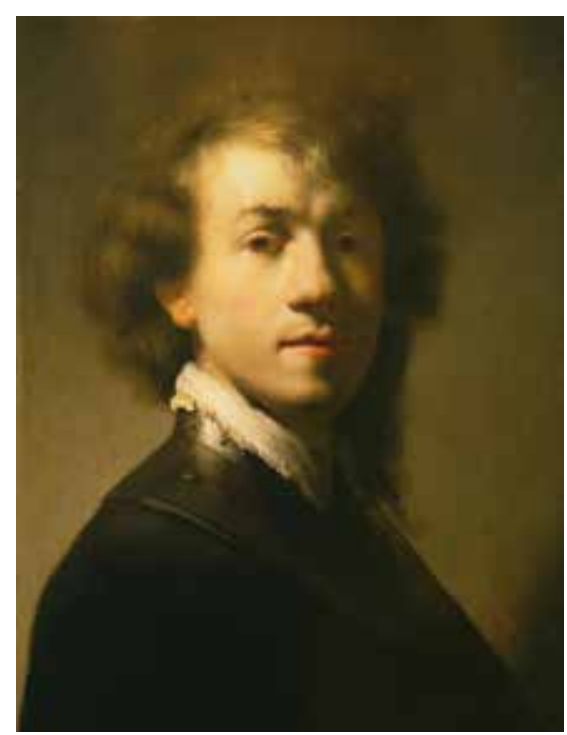

Fig. 3 Studio copy after Rembrandt van Rijn, Portrait of Rembrandt with a Gorget, after ca. 1629, oil on panel, $37.9 \times 28.9 \mathrm{~cm}$. The Hague, Mauritshuis, inv. 148 (artwork in the public domain)

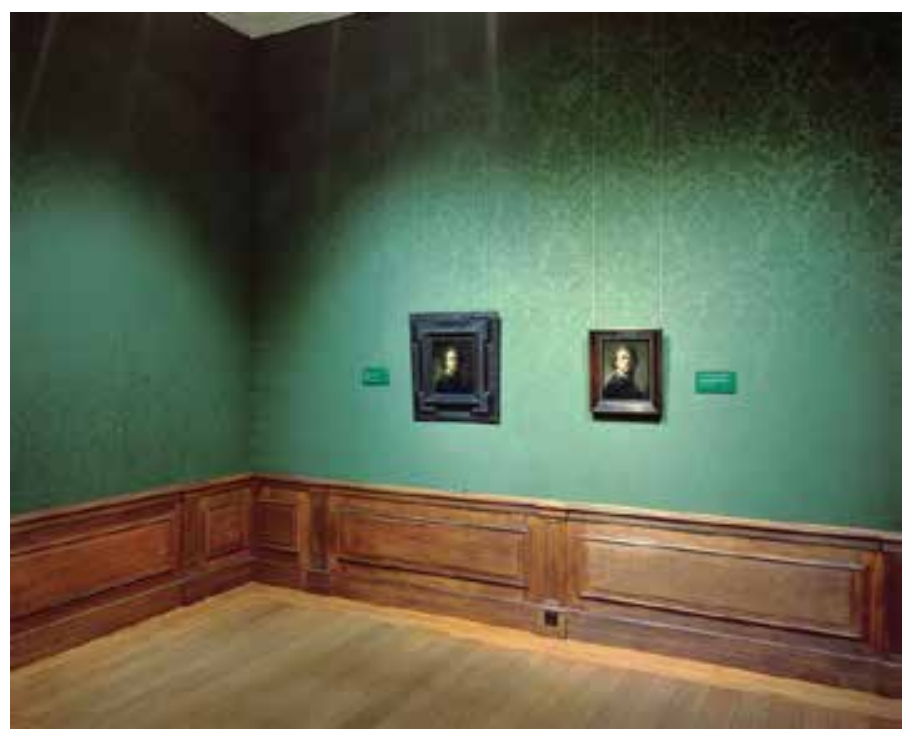

Fig. 4 The paintings from the Mauritshuis, The Hague, and the Germanisches Nationalmuseum, Nuremberg, shown side by side at the exhibition Rembrandt by Himself in The Hague (1999-2000).

One of the paintings that has not been cleaned and restored recently is a painting that for a long time was accepted as an early self-portrait by Rembrandt (inv. 148; fig. 3). It was catalogued as such by the Rembrandt Research Project in 1982 and was then among the most famous works in the Mauritshuis. However, in the summer of 1998 with the aid of infrared images an extensive underdrawing was found on the panel, raising serious doubts about the attribution to Rembrandt. It was the first time that such a drawing on the ground of a painting had ever been found in a Rembrandt. Later it was revealed that the underdrawing exactly matched the contours of another self-portrait in the Germanisches Nationalmuseum in Nuremberg, which proved to be the original painting by Rembrandt that prior to 1998 had been almost universally regarded as a copy after the Mauritshuis painting. This news made headlines, especially when the Mauritshuis presented its own "self-portrait as a young man" as a copy after Rembrandt, as happened at the 
exhibition Rembrandt by Himself in 1999-2000 (fig. 4) ${ }^{16}$ In London and The Hague the panel, now titled Portrait of Rembrandt with a Gorget, hung alongside the painting from Nuremberg. In The Hague, a separate wall was dedicated to the attribution of both paintings. For a short while, the Mauritshuis painting was tentatively attributed to the young Gerrit Dou (1613-1675), Rembrandt's first pupil, but nowadays the label just says "studio copy after Rembrandt," an attribution that hopefully can be fine-tuned in the future.

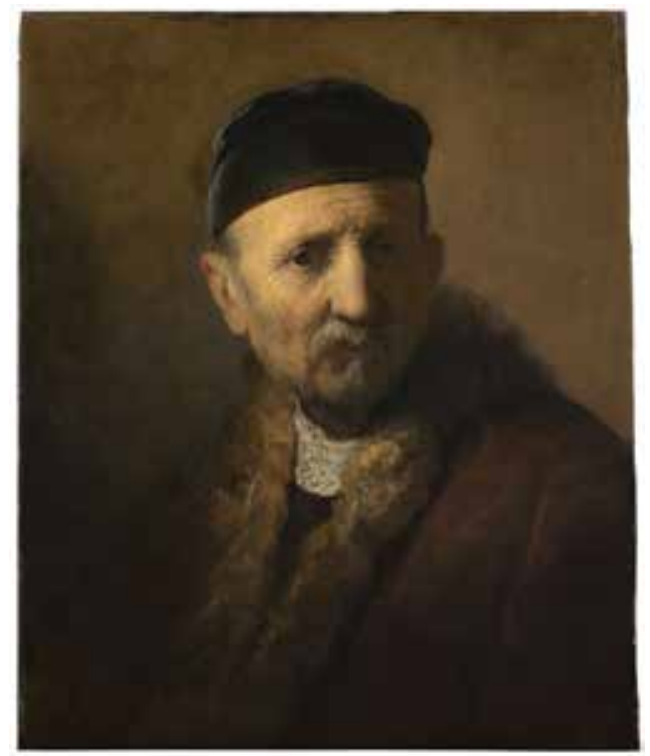

Fig. 5 Rembrandt van Rijn and/or studio of the artist, Tronie of an Old Man, ca. $1630-31$, oil on panel, $46.9 \times 38.8 \mathrm{~cm}$. The Hague, Mauritshuis, Bequest of Abraham Bredius, 1946, inv. 565 (artwork in the public domain

11 At least two works in the Mauritshuis that are attributed to Rembrandt deserve more attention from the museum's conservators and curators. One is the so-called Tronie of an Old Man (inv. 565), a panel that is usually kept in the museum's storage (fig. 5). It entered the collection as part of the bequest of Bredius, who thought that the painting represented Rembrandt's father, Harmen Gerritsz van Rijn (1569-1630), although this proved to be wishful thinking. The attribution is still part of an ongoing debate, even after a restoration completed in 1999. When the painting was recently exhibited in the galleries of the Mauritshuis as a replacement for a Rembrandt that was loaned to another museum, the Tronie of an Old Man was labeled as "Rembrandt and/or studio of." What we know is that the panel came from the same tree as two other paintings that are accepted as by Rembrandt, namely Simeon in the Temple in the Hamburg Kunsthalle and Miner$v a$ in the Berlin Gemäldegalerie. ${ }^{17}$ Recently, the Hague painting was published in the final volume of the Rembrandt Corpus, Rembrandt's Paintings Revisited, where Ernst van de Wetering has attributed Tronie of an Old Man to Rembrandt again, despite the rather coarse and sketchy brushwork. ${ }^{18}$ Thus there is one more attribution to be added to the long list on the painting's page in the Rembrandt database. ${ }^{19}$ I still have difficulty accepting the Mauritshuis Tronie of an Old Man as a completely autograph painting by Rembrandt. The execution of the fur trim of the man's jacket is remarkably flat and weak, and this part of the painting seems to be the work of a studio assistant. Perhaps the painting should simply be considered an oil sketch by the master.

12 Another painting that is not part of the permanent installation of the Mauritshuis is Study of an Old Man (inv. 560; fig. 6), which bears a signature and date next to the man's shoulder: Rembrandt.f. / 1650. The rather abraded signature and date, painted in transparent black on top of the 


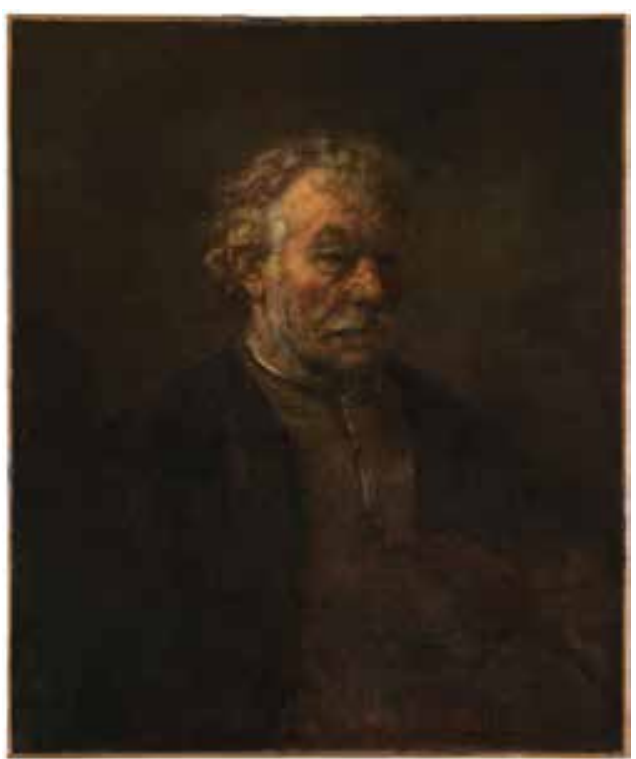

Fig. 6 Attributed to Rembrandt van Rijn, Study of an Old Man, 1650, oil on canvas, $80.5 \times 66.5 \mathrm{~cm}$. The Hague, Mauritshuis, Purchased, 1891, inv. 560 (artwork in the public domain)

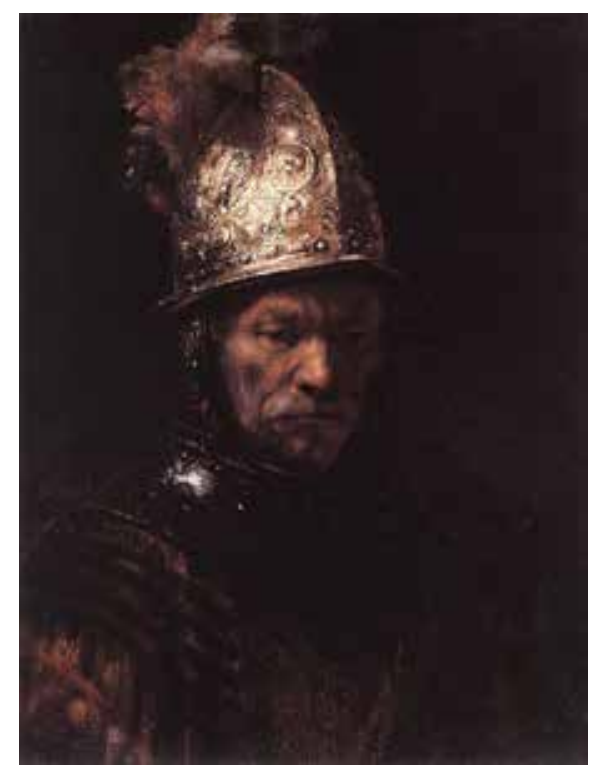

Fig. 7 Formerly attributed to Rembrandt van Rijn, Man with a Golden Helmet, ca. 1650, oil on canvas, $67.5 \times 50.7 \mathrm{~cm}$, Berlin, Staatliche Museen, Gemäldegalerie, inv. $811 \mathrm{~A}$ (artwork in the public domain)

background paint after it had dried, may not be original. ${ }^{20}$ The painting was acquired by the museum in 1891 during the directorship of Bredius, who thought it to be a portrait of Rembrandt's brother, Adriaen van Rijn (1597/98-1652/53). The brown undermodeling (doodverf) in the figure has been left exposed in shadowed areas of the face and hair. The gray background is very abraded, as is a section at bottom right. It is clear that the state of preservation is not ideal, and it has even been assumed that in the past the canvas was rolled up for some time. Before the painting entered the museum's collection, it was subjected to a rather drastic restoration. In the nineteenth century, more than one art historian noted a similarity between the sitter of this painting and the Man with a Golden Helmet in Berlin (fig. 7), ${ }^{21}$ a famous painting of about 1650, which lost its attribution to Rembrandt in 1986 after technical examination carried out by the German museum. Now that Berlin has decided to restore their painting, presently attributed to the circle of Rembrandt, the Mauritshuis is considering a restoration of its own intriguing painting.

13 As a result of the restorations in the Mauritshuis, we have gotten to know the museum's paintings by Rembrandt and his circle more intimately than was ever possible before. But with the continuing development in restoration techniques and research methods, the study of these paintings will remain a work in progress. It is very regrettable indeed that Walter Liedtke is no longer here to discuss the new developments of this ongoing research and he is greatly missed by all of us at the Mauritshuis.

\section{Acknowledgements}

I would like to thank Dr. Emilie Gordenker, Director of the Mauritshuis, for her comments on an earlier draft of this text. This article could not have been written without the extensive research and many publications of past and present curators and conservators working for the Mauritshuis. I thank all of them warmheartedly. 
Quentin Buvelot has been the Senior Curator of the Mauritshuis, The Hague, since 2008. With Desmond Shawe-Taylor, Surveyor of the Queen's Pictures, he curated the exhibition Masters of the Everyday: Dutch Artists in the Age of Vermeer (London, Queen's Gallery; Edinburgh, Queen's Gallery; The Hague, Mauritshuis, 2015-17). Together they wrote the catalogue accompanying this exhibition of Dutch genre paintings from the Dutch Golden Age. On the occasion of the reopening of the renovated and expanded Mauritshuis in June 2014, Buvelot organized the exhibition Mauritshuis—The Building and published a monograph on the building and the history of its interior, as well as a reconstruction of the former garden of the Mauritshuis.

\section{Q.Buvelot@mauritshuis.nl}

\section{List of Illustrations}

Fig. 1 Rembrandt van Rijn, Saul and David, ca. 1651-54 and ca. 1655-58, oil on canvas, $130 \mathrm{x}$ $164.5 \mathrm{~cm}$. The Hague, Mauritshuis, Bequest of Abraham Bredius, 1946, inv. 621 (artwork in the public domain)

Fig. 2 The 3D reconstruction of the original size of Rembrandt's Saul and David, made by Océ Technologies and Delft University of Technology, 2015.

Fig. 3 Studio copy after Rembrandt van Rijn, Portrait of Rembrandt with a Gorget, after ca. 1629, oil on panel, $37.9 \times 28.9 \mathrm{~cm}$. The Hague, Mauritshuis, inv. 148 (artwork in the public domain)

Fig. 4 The paintings from the Mauritshuis, The Hague, and the Germanisches Nationalmuseum, Nuremberg, shown side by side at the exhibition Rembrandt by Himself in The Hague (19992000).

Fig. 5 Rembrandt van Rijn and/or studio of the artist, Tronie of an Old Man, ca. 1630-31, oil on panel, 46.9 x $38.8 \mathrm{~cm}$. The Hague, Mauritshuis, Bequest of Abraham Bredius, 1946, inv. 565 (artwork in the public domain)

Fig. 6 Attributed to Rembrandt van Rijn, Study of an Old Man, 1650, oil on canvas, 80.5 x $66.5 \mathrm{~cm}$. The Hague, Mauritshuis, Purchased, 1891, inv. 560 (artwork in the public domain)

Fig. 7 Formerly attributed to Rembrandt van Rijn, Man with a Golden Helmet, ca. 1650, oil on canvas, 67.5 x $50.7 \mathrm{~cm}$, Berlin, Staatliche Museen, Gemäldegalerie, inv. 811 A (artwork in the public domain)

${ }^{1}$ Hubert von Sonnenburg and Walter Liedtke et al., Rembrandt/Not Rembrandt in the Metropolitan Museum of Art: Aspects of Connoisseurship, 2 vols., exh. cat. (New York: Metropolitan Museum of Art, 1995).

${ }^{2}$ See Emilie Gordenker, "Saul and David Reconsidered-Part 1," Mauritshuis in Focus 28, no. 2 (2015): 6-10; and Gordenker, "Saul and David Reconsidered-Part 2," Mauritshuis in Focus 28, no. 2 (2015): 12-22. This bulletin was published to accompany the exhibition, which ran from June 11 to September 13, 2015.

${ }^{3}$ For a list of members of the research and conservation team, see Gordenker, "Saul and David 
Reconsidered-Part 2," 22; for the treatment and references to earlier literature on the subject, see also Emilie E. S. Gordenker and Petria Noble, "Rembrandt's 'Saul and David' at the Mauritshuis: A Progress Report," JHNA 5, no. 2 (Summer 2013). http://dx.doi.org/10.5092/ jhna.2013.5.2.11 ${ }^{4}$ For an overview of these paintings, see Quentin Buvelot, Royal Picture Gallery Mauritshuis: A Summary Catalogue (The Hague: Mauritshuis/Zwolle: Waanders, 2004): 256-63, nos. 145, 146, 147, 149, 584, 598, 685, 707, 840, 1118, and 621. Rembrandt's Portrait of an Elderly Man (inv. 1118) has not been restored by the museum since its acquisition in 1999 as it is in a very good condition and its esthetic appearance is good.

${ }^{5}$ Marjolein de Boer, Josefine Leistra, and Ben Broos, Bredius, Rembrandt en het Mauritshuis!!!: Een eigenzinnig directeur verzamelt, exh. cat. (The Hague: Mauritshuis/Zwolle: Waanders, 1991). ${ }^{6}$ Norbert Middelkoop et al., Rembrandt under the Scalpel: The Anatomy Lesson of Dr Nicolaes Tulp Dissected, exh. cat. (The Hague: Mauritshuis, 1998).

7 These publications are all listed in the museum's annual reports.

${ }^{8}$ Ben Broos, Intimacies and Intrigues: History Painting in the Mauritshuis (The Hague: Mauritshuis/Snoeck: Ghent, 1993), nos. 30-34; Ben Broos and Ariane van Suchtelen et al., Portraits in the Mauritshuis, 1430-1790 (The Hague: Mauritshuis/Zwolle: Waanders, 2004), nos. 46-50.

${ }^{9}$ See note 4.

${ }^{10}$ Ary Bob de Vries, Magdi Tóth-Ubbens, and Wiebo Froentjes, Rembrandt in the Mauritshuis, ed. Debora Hensbroek-van der Poel (Alphen aan den Rijn: Sijfhoff, 1978).

${ }^{11}$ Petria Noble et al., Preserving our Heritage: Conservation, Restoration and Technical Research in the Mauritshuis (The Hague: Mauritshuis/Zwolle: Waanders, 2009), nos. 6-9.

${ }^{12}$ Wietske Donkersloot, "The Rembrandt Database: A Unique Website for Rembrandt Scholars," Mauritshuis in Focus 25, no. 3 (2012): 6-11.

${ }^{13}$ http://www.rembrandtdatabase.org/Rembrandt/cms/contributors

${ }^{14}$ Ariane van Suchtelen, Rembrandt in the Mauritshuis (The Hague: Mauritshuis/Zwolle: Waanders, 2006).

${ }^{15}$ See the reproductions in Quentin Buvelot, "Mauritshuis Frames," Mauritshuis in Focus 27, no. 1 (2014): 12.

${ }^{16}$ See Edwin Buijsen in Christopher White and Quentin Buvelot, eds., Rembrandt by Himself, exh. cat. (London: National Gallery; The Hague: Mauritshuis/Zwolle: Waanders, 1999), no. 14b; see also Ariane van Suchtelen in Broos and van Suchtelen, Portraits in the Mauritshuis, no. 51, with references to all the literature.

${ }^{17}$ See Quentin Buvelot in Broos and van Suchtelen, Portraits in the Mauritshuis, 309, no. 565.

${ }^{18}$ Ernst van de Wetering, Rembrandt's Paintings Revisited: A Complete Survey, vol. 6 of Corpus of Rembrandt Paintings(Houten: Springer, 2015), 503-4, no. 46.

${ }^{19}$ http://www.rembrandtdatabase.org/ Rembrandt/painting/2950/tronie-of-an-old-man

${ }^{20}$ See the technical description by Caroline van der Elst and Petria Noble in Broos and van Suchtelen, Portraits in the Mauritshuis, 309.

${ }^{21}$ De Vries, Rembrandt in the Mauritshuis, 138 and fig. 111.

\section{Bibliography}

Boer, Marjolein de, Josefine Leistra, and Ben Broos. Bredius, Rembrandt en het Mauritshuis!!!: Een eigenzinnig directeur verzamelt. Exh. cat. The Hague: Mauritshuis/Zwolle: Waanders, 1991. 
Broos, Ben. Intimacies and Intrigues: History Painting in the Mauritshuis. The Hague: Mauritshuis/ Ghent: Snoeck, 1993.

Broos, Ben, and Ariane van Suchtelen, with contributions by Quentin Buvelot, Guus Sluiter, Petria Noble, Peter van der Ploeg, Hans Vlieghe and Frederik Duparc, with an introductory essay by Rudi Ekkart. Portraits in the Mauritshuis, 1430-1790. Edited by Quentin Buvelot. The Hague: Mauritshuis/Zwolle: Waanders, 2004.

Buvelot, Quentin. Royal Picture Gallery Mauritshuis: A Summary Catalogue. The Hague: Mauritshuis/Zwolle: Waanders, 2004.

Buvelot, Quentin. “Mauritshuis Frames.” Mauritshuis in Focus 27, no. 1 (2014): 6-12.

Donkersloot, Wietske. “The Rembrandt Database: A Unique Website for Rembrandt Scholars." Mauritshuis in Focus 25, no. 3 (2012): 6-11.

Gordenker, Emilie. "Saul and David Reconsidered-Part 1." Mauritshuis in Focus 28, no. 2 (2015): 6-10.

Gordenker, Emilie. "Saul and David Reconsidered-Part 2." Mauritshuis in Focus 28, no. 2 (2015): $12-22$.

Gordenker, Emilie E. S., and Petria Noble. "Rembrandt's 'Saul and David' at the Mauritshuis: A Progress Report." JHNA 5, no. 2 (Summer 2013). http://dx.doi.org/10.5092/jhna.2013.5.2.11

Middelkoop, Norbert, Petria Noble, Jørgen Wadum, and Ben Broos. Rembrandt under the Scalpel: The Anatomy Lesson of Dr Nicolaes Tulp Dissected. Exh. cat. The Hague: Mauritshuis, 1998.

Noble, Petria, Sabrina Meloni, Carol Pottasch, and Peter van der Ploeg. Preserving our Heritage: Conservation, Restoration and Technical Research in the Mauritshuis. Edited by Epco Runia. The Hague: Mauritshuis/Zwolle: Waanders, 2009.

Sonnenburg, Hubert von, and Walter Liedtke, with Carolyn Logan, Nadine M. Orenstein, and

Stephanie S. Dickey. Rembrandt/Not Rembrandt in the Metropolitan Museum of Art: Aspects of Connoisseurship. 2 vols. Exh. cat. New York: Metropolitan Museum of Art, 1995.

Suchtelen, Ariane van. Rembrandt in the Mauritshuis. The Hague: Mauritshuis/Zwolle: Waanders, 2006.

Vries, Ary Bob de, Magdi Tóth-Ubbens, and Wiebo Froentjes. Rembrandt in the Mauritshuis. Edited by Debora Hensbroek-van der Poel. Alphen aan den Rijn: Sijfhoff, 1978.

Wetering, Ernst van de. Rembrandt's Paintings Revisited: A Complete Survey. Vol. 6 of Corpus of Rembrandt Paintings. Houten: Springer, 2015. 
White, Christopher, and Quentin Buvelot, eds. Rembrandt by Himself. Exh. cat. London: National Gallery; The Hague: Mauritshuis/Zwolle: Waanders, 1999.

Recommended Citation:

Quentin Buvelot, "Rembrandt in the Mauritshuis: Work in Progress," JHNA 9:1 (Winter 2017), DOI: 10.5092/jhna.2017.9.1.11 